\title{
Article
}

\section{Authors' response to comments on "Flame retardants in UK furniture increase smoke toxicity more than they reduce fire growth rate"}

Mckenna, Sean Thomas, Birtles, Robert, Dickens, Kathryn, Walker, Richard, Spearpoint, Michael, Stec, Anna A and Hull, T Richard

Available at http://clok.uclan.ac.uk/24781/

Mckenna, Sean Thomas, Birtles, Robert, Dickens, Kathryn ORCID: 0000-00030925-1538, Walker, Richard, Spearpoint, Michael, Stec, Anna A ORCID: 00000002-6861-0468 and Hull, T Richard ORCID: 0000-0002-7970-4208 (2019) Authors' response to comments on "Flame retardants in UK furniture increase smoke toxicity more than they reduce fire growth rate". Chemosphere, 232 . pp. 512-515. ISSN 0045-6535

It is advisable to refer to the publisher's version if you intend to cite from the work. http://dx.doi.org/10.1016/j.chemosphere.2018.10.178

For more information about UCLan's research in this area go to http://www.uclan.ac.uk/researchgroups/ and search for <name of research Group>.

For information about Research generally at UCLan please go to http://www.uclan.ac.uk/research/

All outputs in CLoK are protected by Intellectual Property Rights law, including Copyright law. Copyright, IPR and Moral Rights for the works on this site are retained by the individual authors and/or other copyright owners. Terms and conditions for use of this material are defined in the policies page. 


\section{Accepted Manuscript}

Authors' response to comments on "Flame retardants in UK furniture increase smoke toxicity more than they reduce fire growth rate"

Sean McKenna, Robert Birtles, Kathryn Dickens, Richard Walker, Michael Spearpoint, Anna A. Stec, T.Richard Hull

PII: S0045-6535(18)32049-6

DOI: 10.1016/j.chemosphere.2018.10.178

Reference: CHEM 22440

To appear in: Chemosphere

Received Date: 24 August 2018

Accepted Date: 25 October 2018

Please cite this article as: Sean McKenna, Robert Birtles, Kathryn Dickens, Richard Walker, Michael Spearpoint, Anna A. Stec, T.Richard Hull, Authors' response to comments on "Flame retardants in UK furniture increase smoke toxicity more than they reduce fire growth rate", Chemosphere (2018), doi: 10.1016/j.chemosphere.2018.10.178

This is a PDF file of an unedited manuscript that has been accepted for publication. As a service to our customers we are providing this early version of the manuscript. The manuscript will undergo copyediting, typesetting, and review of the resulting proof before it is published in its final form. Please note that during the production process errors may be discovered which could affect the content, and all legal disclaimers that apply to the journal pertain. 


\title{
1 Authors' response to comments on
}

\author{
"Flame retardants in UK furniture
}

3 increase smoke toxicity more than they

4 reduce fire growth rate"

5

6

7

8

9

10

Sean McKenna ${ }^{1}$, Robert Birtles ${ }^{1,2}$, Kathryn Dickens ${ }^{1}$, Richard Walker ${ }^{1,3}$, Michael Spearpoint ${ }^{4,5}$, Anna A Stec ${ }^{1}$ and T Richard Hull ${ }^{1 *}$.

1. Centre for Fire and Hazard Science, University of Central Lancashire, Preston, PR1 2HE, UK

2. Greater Manchester Fire and Rescue Service, Manchester, M4 5HU, UK

3. West Midlands Fire Service Headquarters, 99 Vauxhall Road, Birmingham B7 4HW, UK

4. Department of Civil and Natural Resources Engineering, University of Canterbury, Christchurch 8140, New Zealand

5. Olsson Fire and Risk, Manchester, M4 6WX, UK

*Corresponding author: trhull@uclan.ac.uk

\section{Introduction}

The publication "Flame retardants in UK furniture increase smoke toxicity more than they reduce fire growth rate" (McKenna et al., 2017) has drawn responses from two individuals expressing concerns 
that such studies could lead to a reduction in flame retardant use in furniture. Such debate is very welcome, and unlike the "fake news" currently in the media spotlight, peer-reviewed publications provide a permanent and definitive record of what was said and what was not. By setting the evidence out openly, scientists are in a position to draw appropriate conclusions.

The authors of both responses have recently published work funded by the flame retardant industry (Hirschler, 2015; Blais et al., 2013). It is unfortunate that both respondents appear to have missed key passages in the original paper, necessitating quotes from it to address the responses.

Both responses refer to the work as a series of tests, suggesting pass/fail or quantifying some performance criteria. We believe it is better to consider it as a series of experiments designed to understand why the fire death rate in the UK had not fallen more sharply than that of countries without furniture flammability regulations. The working hypothesis was that gas-phase flame retardants used in upholstered furniture may increase the yields of the main asphyxiants, carbon monoxide and hydrogen cyanide (Molyneux et al., 2014a). We believe this was adequately demonstrated in the paper for the sofa-bed compositions investigated.

Dr Blais complains that the term "chemical flame retardants" is "is not a scientific description but an attempt to declare all flame retardants (FRs) as "chemicals" in order to create an emotional perception of chemicals being generally bad.". We believe it is a useful distinction. The special weave of CottonSafe, or the use of an interliner are two methods of reducing the flammability which do not use chemical flame retardants. As the majority of our authors are professional chemists (the remaining three being fire safety engineers), we do not see the use of chemicals as pejorative, merely a useful distinction between substances of homogeneous chemical composition ("chemicals"), rather than the diverse mixtures of compounds found elsewhere. 
After discussing aspects of the paper, Dr Hirschler makes a series of value judgements which are incorrect and unjustified. They seem designed to lull the reader who doesn't follow his arguments into accepting his perspective. For example:

"The large-scale fire tests conducted do nothing more than demonstrate that a severe enough ignition source will cause virtually any combustible material to ignite." The fire tests did a great deal more than that, showing: similar times to ignition; different toxic product yields; different maximum temperatures; and somewhat different mass losses for fire retardant and non-fire retardant furniture formulations. They also contribute to our understanding of why the UK has a high rate of upholstered furniture fire related deaths.

"For all the reasons stated above, clearly all the large-scale fire test results are severely faulty and should be discarded." The large scale tests were the most significant part of this work and raise important questions about the value of adding flame retardants to furniture. At the very least the evidence presented should make it clear that further work is needed.

"Thus, this severely flawed work contradicts not just the publish literature but its own results." This statement refers to the comparative performance of UK and US furniture in the crib 5 test which the UK furniture was designed to pass. It makes no reference to our original paper or contradictions therein, and is therefore completely without justification.

"This means that the equation used to predict incapacitation in this article has been shown to exaggerate the effects of heteroatoms, such as halogen atoms." Within ISO TC 92 SC3, which deals with smoke toxicity, there is an industry-backed campaign to ignore experimental data showing the level of hydrogen cyanide at which baboons become unconscious, and increase the tenability limit for other toxicants. The equations used in the original paper have been in the existing standard for 
over a decade, and are current and still valid, unlike the industry-backed approach proposed by Professor Pauluhn and lauded by Dr Hirschler.

One aspect that neither correspondent made any comment on was the large body of work showing the harmful effects of many flame retardants, which were briefly summarised in the original paper. Given the obvious need to balance the risks and benefits of flame retardants, it is unclear whether the data on health and environmental risks are now accepted by those in favour of wider deployment of flame retardants, or whether they are dismissing such research as irrelevant.

\section{Fire Statistics}

Dr Hirschler asks why we did not use the report by Gary Stevens. This was described in the original paper.

"In a report commissioned by the flame retardant industry (Emsley et al., 2005), and a subsequent report for the UK government (Greenstreet Berman Ltd, 2009), it was argued that "the introduction of fire-safe furniture [in the UK] from 1988 onwards is estimated to have resulted in at least $50 \%$ of the estimated 2002 savings in injuries and domestic fire deaths", the other $50 \%$ being attributed to low cost smoke detectors. Factors such as changes in cigarette smoking habits, the change from exposed flame heating sources and a general improvement in standard of living were not considered (Hull et al., 2014)." No justification was provided in either of the Stevens' reports for attributing 50\% of the fire death reduction to furniture flame retardants. It should also be noted that the data in that report is over 20 years old.

In the introductory summary, Dr Blais dismisses the work on UK and New Zealand statistics as "of less important and low contribution because it does not lead to meaningful conclusions" but then goes on to discuss it later in the response. 
Dr Blais argues that "Comparison of fire deaths of just two countries in the world for a very specific time span and not including fire injuries, fire losses, and number of fires is of questionable validity as a scientific argument. He goes on to complain that the data was not available on the link provided. The links to the digital yearbook are still valid, but it takes time to find the data from the text. Unfortunately, the University of Canterbury website has been restructured so the original link no longer works, but the thesis is still available (Wong, 2001). Similarly, the New Zealand Fire Service has been renamed Fire and Emergency New Zealand, and the statistical reports do not appear to be available on-line. Similarly, the UK data, from 1955, do not appear in a single document on the fire statistics website, they have been collected from annual reports over that period. In addition to the New Zealand data, our original paper quotes the European Commission report which shows a similar pattern of reduction in fire death rates across the wealthier European countries.

"A detailed study produced for the European Commission (Arcadis EBRC, 2011) on the risks and benefits of adding fire retardants to furniture, analysed the fire fatality data from individual European countries with different levels of flammability regulation. While the study acknowledged the difficulty in comparing statistics from different countries, it concluded that "in some instances, drops in the number of fire deaths coincide with the introduction of non-flammability requirements for domestic consumer products. In other instances, however, there is no change in the on-going trend of fire deaths. This suggests that these numbers do not reflect the stringency of nonflammability requirements, respectively that non-flammability requirements do not visibly decrease the number of fire deaths."

It is a matter of speculation why both respondents chose to ignore the findings of the European Commission study, but it certainly weakens the argument that the New Zealand data had been taken in isolation. Surprisingly, more precise fire death rates do not appear to be readily available for most countries. There are also inconsistencies, such as whether road traffic accident or murder by arson, 
120

121

122

123

124

127

are recorded as fire deaths in particular jurisdictions. On that basis, New Zealand seemed to be a good choice and the data was available. Within the constraints of the paper there was insufficient space for a fuller statistical analysis.

\section{Mattress Formulations}

Both responses draw attention to the fact that the mattresses were not commercial, and therefore not representative of typical furnishings. We deliberately asked the manufacturer to make the mattresses so that they were consistent with each other: the three foam mattresses having the same thickness of foam and the same thickness of polyester comfort layer, using comparable fabric covers with different flame retardant treatments. This would be unlikely to be the case if commercial products had been selected, and would have involved additional purchases to dissect them and determine their composition. Rather tellingly, Dr Blais goes on to say "there are dozens of details that matter to fire behavior in the complex design of furniture". The implication is that mattresses have to be carefully engineered in order to achieve a pass in a regulatory test. While this is probably true, it is a very unfortunate situation, and goes some way towards explaining why UK furniture is involved in so many fatal fires.

\section{Use of a Crib 7 Ignition Source}

Both respondents express concerns about the use of a "crib 7" ignition source, rather than a "crib 5". The difference is that the fabric and filling in three of the four mattresses have been designed to resist ignition by a crib 5 source. The crib 5 source is meant to represent two single sheets of newspaper while the crib 7 is meant to represent 4 double sheets of newspaper (BS 5852, 2006). The decision was clearly explained in the original paper. 
143

"In order to ensure that each mattress ignited first time, a larger, No. 7 crib, containing $125 \mathrm{~g}$ of Scots Pine (Pinus Silvestris), arranged as an open frame to give adequate ventilation, was employed to ensure sustained ignition, since three of the four compositions were supplied as having already resisted ignition using the No. 5 wooden crib (containing $17 \mathrm{~g}$ wood)."

It was shown in the paper that UK fire deaths are driven by smoke toxicity in living and bedrooms, so it is highly probable that fires involving the UK's flame retarded upholstered furniture are the main cause of death. Since this furniture has to pass a crib 5 test in order to be sold in the UK, using a crib 5 source would not have addressed the conundrum of why the UK has a fire death rate to comparable to countries without flame retardant furniture. To describe the crib 7 source as "powerful" in anything but a relative sense is gross exaggeration. How many people consider that leaving four sheets of newspaper on the sofa, is deploying a potentially powerful ignition source?

In our study we were surprised to find that "for three of the four formulations, in the large scale test, there was very little difference in the time to ignition or fire growth rate, despite two of the three containing flame retardants." Dr Blais comments "The observation that there is very little difference in time to ignition is due to the significantly larger ignition source used". We believe that the general population, or customers purchasing flame retardant furniture, would expect a significantly longer time to ignition from flame retardant furniture (indeed many believe it will not burn at all). Only industry insiders are aware of the marginal benefits they provide.

Dr Blais asks why another set of eight sofa-beds were not tested using a crib 5 source. Given that the materials were sold on the assumption that they would not ignite using a crib 5 source, such verification seems rather wasteful. 
167

\section{Bench-Scale Tests}

Referring to the cone calorimeter work, Dr Hirschler expresses concerns over the thickness of the comfort layer in proportion to a full-scale mattress. This is an inevitable problem of bench scale assessment of real fire behaviour. For the samples to be proportionate, a finer fabric would also have to be woven, and a thinner polyester layer used. In this work we use the same composition as the sofa-bed mattress, to see how they behaved in a small scale test. However, because the benchscale test supports his view that flame retardants are always beneficial, he says it shows "the UK flame retarded system is vastly superior in fire performance to all others". Readers can judge for themselves whether they place more faith in a $100 \times 100 \times 25 \mathrm{~mm}^{3}$ test than they do in a full scale sofa-bed burn, but they produced very clearly different results.

\section{Performance of Gas Phase Flame Retardants in Large Scale Tests}

In his introductory summary, Dr Blais asserts that "the lack of clear explanations or visual photography of the fire puts the validity of the results recorded in the paper in doubt." Typically, furniture is tested in an open calorimeter which is well-ventilated, making it the worst case scenario for flammability but minimising smoke toxicity. This study was designed to simulate a fire in a real room, as found in a typical European dwelling, where most UK fire deaths are reported to occur. Thus, the fire was in a test room, not in the open, hence detailed photographic records are not available. The original paper explains that the fire room was in a steel shipping container with a low level circular ventilation duct and a high level open window, and says "Ignition was observed through a small viewing port in the plasterboard wall." Compared to measured concentrations of carbon monoxide and hydrogen cyanide, the "lack of visual photography" is a weak argument to cast doubt on the validity of the work reported in the paper. 
191

192

193

194

195

196

197

198

199

200

201

202

203

204

205

206

207

208

209

210

211

212

213

214

215

216

In the original paper it explains that "data from large scale fires (Andersson et al., 2005; Blomqvist et al., 2001) in enclosures show much higher levels of both asphyxiant gases $\mathrm{CO}$ and $\mathrm{HCN}$ under conditions of developed flaming than those from small, well-ventilated tests, such as the cone calorimeter (ISO 5660-1, 2015). For a particular material, under different fire conditions, the HCN yield has been shown to rise proportionately with the CO yield (Molyneux et al., 2014b; Wang et al., 2011; Purser et al., 2008)."

Dr Blais asserts that "The most egregious issue with the paper is comparing the cyanide production as a function of flame retardant when the foams used in the experiments are not even close to comparable. UK/CH foams with flame retardant have $12.88 \%$ by weight $\mathrm{N}$ while the $\mathrm{EU}$ foam is only $5.5 \% \mathrm{~N}$. This limits the total possible HCN that can be produced by the EU foam to less than $50 \%$ of that for the UK/CH foam." With hindsight, the uncertainty of the analysis in Table 3 should have been commented on. In subsequent work we have found inconsistencies in our CHNS measurements of commercial materials (and we doubt that there are commercially available polyurethane foams with such low nitrogen content). Additionally, in a number of other studies (Purser, 2008) it has been shown that typically around $10 \%$ of fuel nitrogen remains as hydrogen cyanide in the effluent, although, like carbon monoxide, more hydrogen cyanide is present within the flame. This is indeed why gas-phase flame retardants which quench the flame reactions, such as brominated aromatics used in the fabric or the trichloroalkyl phosphates used in foam, increase the yield of both carbon monoxide and hydrogen cyanide.

Under the title "Mechanism of action of flame retardants", Dr Hirschler states that "the addition or incorporation of flame retardants (or the use of any process that lowers flammability) will result in less complete combustion...[because] the exothermic combustion reactions are partially inhibited." This statement fails to make the important distinction between gas phase flame retardants, which favour the formation of key toxicants, including carbon monoxide and hydrogen cyanide, and condensed phase fire retardants, which often work by forming a protective layer, keeping the fuel in 
217

218

219

220

221

222

the condensed phase, where it will not burn, which do not usually have an adverse effect on the fire toxicity.

Dr Blais observes that "inclusion of FR in the materials results in a smaller fire that does less tissue damage [through burns etc] but still produces toxic smoke. It becomes a race as to which kills you heat or toxic smoke. FR slowed down the heat release resulting in toxicity winning the race. This is demonstrated well in the heat, $\mathrm{CO}$ and HCN graphs in figures 7, 8 and 9 in this paper." This is a valid point, and one that we as authors of this study would like to see debated further, based on further experimental data. However, the argument will not be resolved if ignition sources are selected that just ignite one item, while just failing to ignite another.

Dr Blais then amplifies a fourth benefit of flame retardants, that there is "a reduction in the amount of materials consumed which affects the total heat release and total smoke produced. FR-protected materials often are not completely consumed resulting in lower total heat release and lower total toxic smoke." This is a valid point and makes another useful contribution to the debate. Indeed, in conducting comparative fire hazard assessments on any two sofas, by knowing the extent of burning, and the toxic potency of the smoke is the only way a valid assessment could be undertaken. Unfortunately, while this is information that is probably well-known by test laboratories such as SWRI, it is not generally available in the public domain.

\section{Funding}

Dr Hirschler incorrectly describes CottonSafe as the project sponsor, while Dr Blais maintains that funding of senior academics has not been disclosed. As University academics we have a degree of autonomy to pursue research, such as this, following our own instincts. As stated in the 
acknowledgements, "We would all like to thank Mark Dowen of Cottonsafe Natural Mattress for provision of samples, help and advice". CottonSafe did manufacture and supply, at our request, the eight sofa-bed mattresses, and samples of the foams and fabrics for our bench scale testing. They also loaned a steel frame in order to avoid the complication of a wood frame burning to help differentiate the different mattress formulations. Apart from that outlined in the

Acknowledgements, no funding was received from any source, other than our respective employers.

\section{References}

Andersson, B., Markert, F., Holmstedt, G. (2005) Combustion products generated by hetero-organic fuels on four different fire test scales. Fire Safety Journals, 40(5), pp. 439-465

Arcadis EBRC (2011) Report for European Comission (DG Health and Consumers) - Evaluation of data on flame retardants in consumer products. Final report 17.020200/09/549040, Brussels, http://ec.europa.eu/consumers/safety/news/flame_retardant_substances_study_en.pdf

Blais, M., Carpenter, K. (2013) Flexible polyurethane foams: A comparative measurement of toxic vapors and other toxic emissions in controlled combustion environments of foams with and without fire retardants. Fire Technology, 51(1), pp. 3-18

Blomqvist, P., Lonnermark, A. (2001) Characterization of the combustion products in large-scale fire tests: comparison of three experimental configurations. Fire and Materials, 25(2), pp. 71-81

BS 5852:2006 Methods of assessment of the ignitability of upholstered seating by smouldering and flaming ignition sources. British Standards, London.

Emsley, A., Lim, L., Stevens, G., Williams, P. (2005) International fire statistics and the potential benefits of fire count-measures. For: European Flame Retardant Association (EFRA), PRC/92/2005/EFRA, May 2005.

Greenstreet Berman Ltd (2009) A statistical report to investigate the effectiveness of the furniture and furnishings (Fire) (Safety) regulations 1988. For: UK Department for Business, Innovation and Skills, December 2009 
Hirschler, M.M. (2015) Flame retardants and heat release: review of traditional studies on products and on groups of polymers. Fire and Materials, 39(3), pp. 207-231

Hull, T.R., Law, R.J., Bergman, Å. (2014) Environmental drivers for replacement of halogenated flame retardants. Polymer Green Flame Retardants, pp. 119-179

ISO 5660-1:2015 Reaction-to-fire tests - Heat release, smoke production and mass loss rate - Part 1: heat release rate (cone calorimeter method) and smoke production rate (dynamic measurement)

McKenna, S.T., Birtles, R., Dickens, K., Walker, R.G., Spearpoint, M.J., Stec, A.A., Hull, T.R. (2018) Flame retardants in UK furniture increase smoke toxicity more than they reduce fire growth rate. Chemosphere, 196, pp. 429-439

Molyneux S., Stec, A.A., Hull, T.R. (2014a) The effect of gas phase flame retardants on fire effluent toxicity. Polymer Degradation and Stability, 106, pp. 36-46

Molyneux, S.A., Stec, A.A., Hull, T.R. (2014b) The correlation between carbon monoxide and hydrogen cyanide in fire effluents of flame retarded polymers, Fire Safety Science, 11, pp. 389403

Purser, D., Purser, J. (2008) HCN yields and fate of fuel nitrogen for materials under different combustion conditions in the ISO 19700 tube furnace and large-scale fires. Fire Safety Science, pp. $1117-1128$

Wang, Z., Jia, F., Galea, E.R. (2011) A generalised relationship between the normalized yields of carbon monoxide and hydrogen cyanide. Fire and Materials, 35(8), pp. 577-591

Wong R, (2001), ME Thesis, University of Canterbury, New Zealand, https://ir.canterbury.ac.nz/handle/10092/8301 